\title{
Thermosensitive devices based on rapidly quenched shape memory alloys
}

\author{
A.V. Shelyakov, S.G. Larin ${ }^{1}$, V.P. Ivanov ${ }^{1}$, V.V. Sokolovski ${ }^{1}$ and A.Yu. Nikiforov \\ Moscow Engineering Physics institute, Kashirskoe Shosse 31, 115409 Moscow, Russia \\ ${ }^{1}$ Master Research Ltd., Prechistenka Street 38, 119034 Moscow, Russia
}

\begin{abstract}
Paper describes a number of thermosensitive devices, including thermal relays, heat sensitive detectors, based on shape memory effect. Thermosensitive part of the devices is made of a small piece of TiNi-based thin ribbon produced by meit spinning technique. Owing to this developed devices are of miniature size, high speed response, narrow temperature hysteresis, low cost. Industrial production of several types of thermosensors was organized. Designs and some characteristics of the devices are presented.
\end{abstract}

\section{INTRODUCTION}

In recent years shape memory alloys (SMAs) have been recognized as effective and promising means for application in various branches of engineering, in the first place in power engineering, instrument-making, space technology, medicine and robotics. It should be noted that even the nature of the shape memory effect (SME) makes the use of SMAs as thermomechanical elements successful. Particularly for the use of SMAs for thermosensitive devices, it is very important to increase the speed of response and the sensitivity of shape memory elements, as well as to widen essentially the application fields of thermosensors through their miniaturization. The one of the perspective materials for solving this problem is SMA foil ribbon.

It is well known that TiNi-based alloys are the most widely used shape memory materials. Addition of ternary alloying element $(\mathrm{Cu}, \mathrm{Fe}, \mathrm{Al}, \mathrm{Zr}, \mathrm{Hf}$, etc.) to near equiatomic $\mathrm{TiNi}$ alloy may markedly affect memory characteristics, in particular temperature and hysteresis of martensitic transformation and SME [1-9]. The ordinary method of ribbon production is ingot processing with sheet rolling. However, thin ribbon of hard-deformed NiTi-based alloys can not be usually produced under industrial conditions using this method, as it is very labour-intensive and costly process. Besides, such conventional technology leads to deterioration of SME properties dealing with formation of brittle phases in alloy structure, and as a rule does not provide uniformity of alloy structure and chemistry along the ribbon length. At the same time method of rapid solidification allows immediately from a melt to produce thin ribbons of required (singlephase) structure and improved thermo-mechanical characteristics. We have developed compositions and production technology of rapidly quenched TiNi-based alloys, and for the first time in the world their commercial manufacture has been achieved. The main advantages of the developed foil ribbon technology are stipulated by the fact that initially amorphous or amorphous-crystalline ribbon structure is formed by means of rapid melt quenching at the cooling rates of $10^{5}-10^{6} \mathrm{deg} / \mathrm{sec}$; and then, under heat treatment, the submicrocrystalline structure is produced with a dispersivity of 1-2 orders finer than that obtained by standard technology. This allows to produce thin ribbon, which, as opposes to ribbon produced by rolling, exhibits higher physical and mechanical properties, higher ductility and homogeneity of SME characteristics along the ribbon length. It should be noted that developed technology is of little stage and lower inputs in comparison with the standard one.

The present work is concerned with development and investigation of thermosensitive devices on the base of rapidly quenched SMA ribbon. 


\section{RAPIDLY QUENCHED SMA RIBBONS}

The TiNi-based alloys were prepared from the high purity metals melted 6 times by using argon arc furnace. Then the obtained ingots were melted in a quartz crucible under a purified atmosphere of inert gas and ejected on to the surface of a copper wheel at a cooling rates of $10^{4}-10^{6} \mathrm{~K} / \mathrm{s}$. Thus, the rapidly solidified $\mathrm{TiNi}(\mathrm{Cu}, \mathrm{Fe}, \mathrm{Al}, \mathrm{Zr}, \mathrm{Hf}$, etc.) alloys were produced by the melt spinning and planar flow casting technique in the form of ribbons of $30-60 \mu \mathrm{m}$ in thickness and up to $20 \mathrm{~mm}$ in width.

In recent time, properties of the melt spun alloys of quasibinary TiNi-TiCu and NiTi-NiHf systems were reported [2,4-9]. At present, industrial production of $\mathrm{TiNiCu}$ foil ribbon is organized and new alloy compositions are developed and produced to reach high temperatures (up to $300^{\circ} \mathrm{C} \div 400^{\circ} \mathrm{C}$ ) and cryogenic temperatures of shape recovery. Some ribbon parameters are listed in Table I.

Table I: Parameters of manufactured and developed SMA thin ribbons

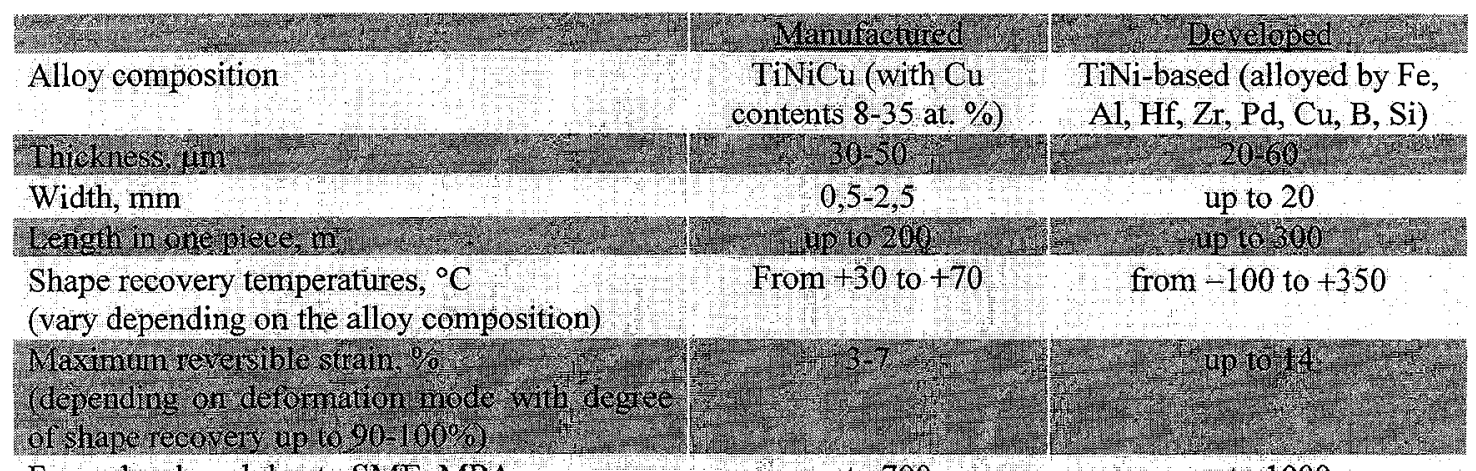

Force developed due to SME, MPA

up to 700

up to 1000

\section{THERMAL RELAYS}

The basic functional element of a thermal relay is made of SMA thin ribbon. When the element is heated above the certain critical temperature, it changes sharply its shape, «recollecting» a shape given previously by means of special thermomechanical treatment. At the same time, it is able to develop the significant mechanical force and indicate the change of temperature, for example, by closing the electrical contacts or modulating the optical signal. After cooling, the element comes back into initial condition. Switching temperature and temperature hysteresis of thermosensor can vary in a wide range due to alloy composition change, as well as the design features.

\subsection{Thermal relay $\mathrm{RT}-002$}

The earlier thermorelay RT-002 design [10] is shown in Fig.1 (normally closed). Inside of the body (1) with leads (2), the spring (3) and TiNiCu thin ribbon ring (4) are located. The combination «spring - ring» is rated in such a way that in «cold» state the contact is closed (or opened for normally opened thermorelay). While heating, the ring restores ring shape given and opens the contact. While consequent cooling, the spring returns the ring in initial («flattened») state and the contact restores. First samples of such thermorelay have been created by 1993. By nowadays, there are four modifications manufactured in Russia at three plants with annual production of about 1200000 pieces. Normally closed thermorelay RT002 (in metal body) now is using as built-in element of thermal (heat sensitive) fire detectors, as well as for protection of devices, equipment and consumer goods from thermal damages. It's possible to use RT002 , hermetically sealed by the covering of 10-20 $\mu \mathrm{m}$ layer of poly-para-xylelen or poly-chlorin-paraxylelen, in aggressive or explosion-dangerous environments. Covering doesn't have influence on thermal characteristics of the relay. 


\subsection{Thermal relays $\mathrm{RT}-1003$, RT-2003}

New thermorelay design [11] is shown on Figures 2 and 3 (normally closed). The body (1) is equipped by immovable contact (2) and movable contact (3) with bent section, on which thermosensitive element of TiNi-based thin ribbon piece (4) is fixed. This piece (4) is pre-strained to the value of elongation not exceeding maximum martensite shift $\xi_{m}$ of SMA thin ribbon (we use $1,0 \div 2,5 \%$ elongation). Geometric dimensions of thin ribbon piece, movable contact and bent section are chosen that movable contact rigidity is less than force developed by thermosensitive element in «heated» state due to SME, but exceeds elastic force of thermosensitive element in «cold» state. The advantages of the thermorelays RT-1003 and RT-2003 are that the force developed by thermosensitive element is considerably higher than the same in earlier thermorelay design. That allows to use lesser piece of expensive enough SMA thin ribbon, at the same time to develop higher contact efforts and so, to obtain less transient contact resistance value $(<0,3$ $\Omega$ ), and also to improve thermorelay fast response and reliability. These thermorelays are fully hermetic making it possible to use them for temperature control in aggressive or explosion-dangerous environments.

Seven modifications of such thermorelay, including ones for operation as built-in element of heat sensitive detectors are developed, for example, a switch with third immovable contact. In 1998, commercial manufacturing of small-scale thermorelay RT-1003 in hermetically sealed durable glass body was started and experimental lot of small-scale thermorelay RT-2003 in hermetically sealed durable metal body was produced. Commercial manufacturing of RT-2003 was started in 1999. RT-1003 can be produced in gas-filled version. It'll be possible to supply RT-2003 in nickel- or gold-plated body.

\subsection{Technical parameters of thermal relays}

General technical characteristics of the thermal relays are presented in Table II. Most of thermorelays have been tested in official testing centers of Russian State Anti-Fire Department. Serially produced thermorelays have switching temperature error not more than $\pm 5 \%$. Particularly precise relay with $\pm 1 \%$ error are produced under special orders. The switching temperatures were tested in conditions of stream of warm air (rate of heating - up to $3{ }^{\circ} \mathrm{C} / \mathrm{min}$ ). As the most important parameter having the influence on speed of response and reliability of a thermorelay is its mass, we tried to minimize the weight of relays. Now the most miniature and fast-responsive relay is RT-2003 one which has maximum mass $0,17 \mathrm{~g}$ and switching time at reaching the switching temperature less than $0,1 \mathrm{sec}$. To increase the lifetime of the relay which depends not only on the lifetime of the ribbon, but mostly on the corrosion of the contacts, we have created fully hermetically sealed versions.

\subsection{Radiation hardness of thermal relays}

The irradiation of thermal relays was carried out in normally closed mode. The power supply voltages were $24 \mathrm{~V}$ with $10 \mathrm{~mA}$ current flow (which corresponds to normal conditions) and $40 \mathrm{~V}$ with $100 \mathrm{~mA}$ (in limit conditions).

In order to check switching temperature and temperature hysteresis width the sample is placed (hanged-up) in the center of thermo-camera with $(15 \ldots 25)^{\circ} \mathrm{C}$ temperature for not less than 15 minutes. The temperature is increased with not more than $1^{\circ} \mathrm{C} /$ min rate up to the switching moment. The switching temperature back to the closed mode was evaluated while the temperature was slowly relaxed to the normal conditions. We used a ventilator in order to avoid temperature instability within the bulk of the camera. The total resistance values were measured under laboratory conditions using digital ohmmeter with accuracy not less than $1 \%$.

The used radiation sources, dosimeter types and dosimetry errors are summarized in Table 3. 


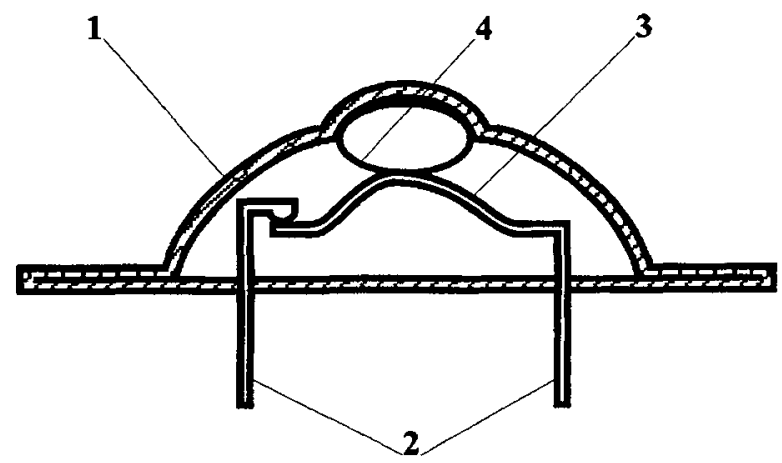

Figure 1: Thermorelay RT-002

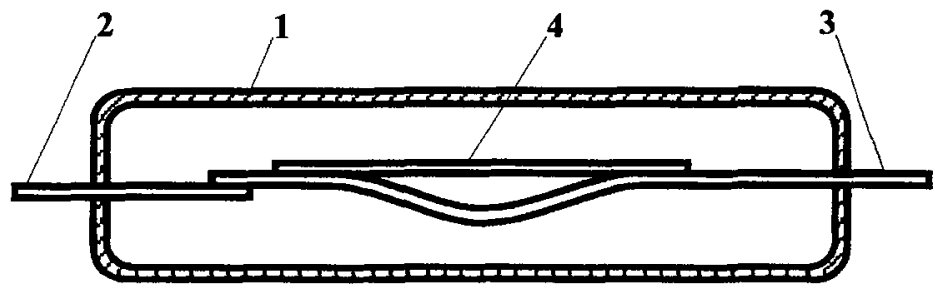

Figure 2: Thermorelay RT-1003

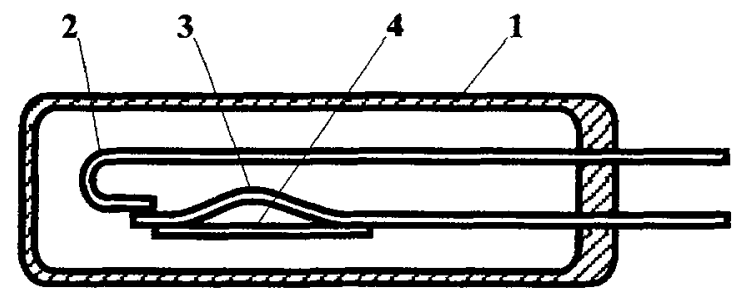

Figure 3: Thermorelay RT-2003 
Table 2: Technical characteristics of some thermorelays

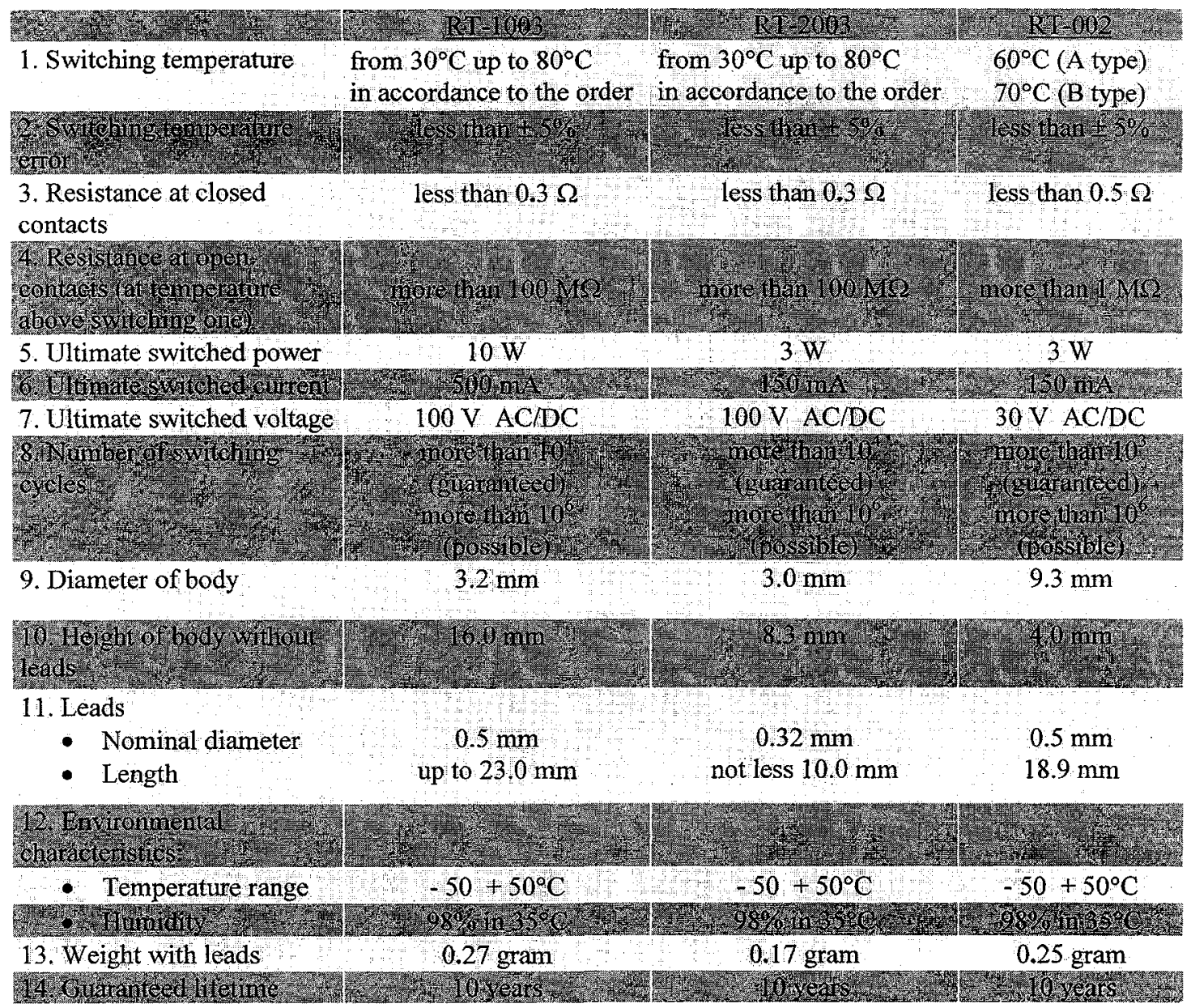

Table 3: Radiation sources, dosimeters and dosimetry errors

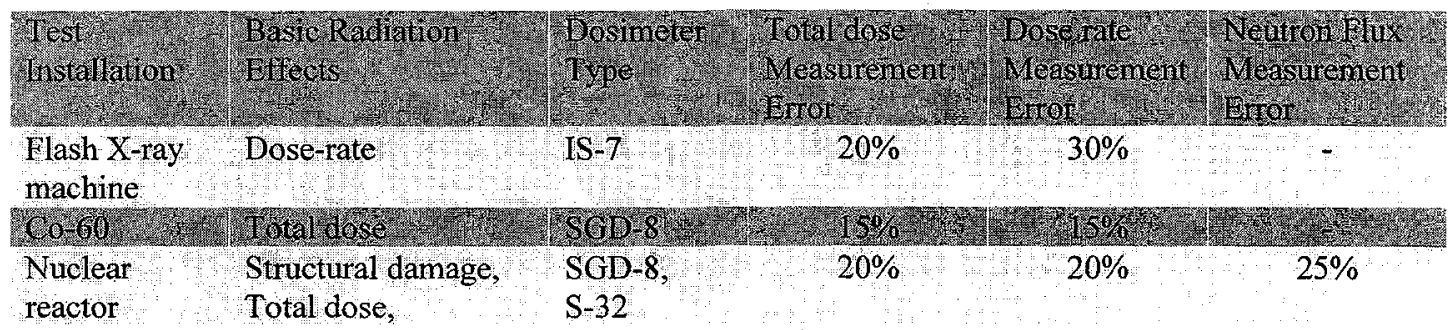


The test thermal relay RT-2003 were irradiated with the following levels: dose rate $10^{8} \mathrm{rad}(\mathrm{Si}) / \mathrm{s}$, total dose $10^{3} \mathrm{rad}(\mathrm{Si}) / \mathrm{s}$ and neutron flux $10^{11} \mathrm{n} / \mathrm{cm}^{2}$ irradiation. Relay parameters were measured after each radiation influence and were as follows:

total deviations of the switching temperature from initial values did not exceed 3,6\%;

temperature hysteresis width - less than $2.2^{\circ} \mathrm{C}$;

total resistance in closed mode - less than $0.3 \mathrm{Ohm}$;

total resistance in open mode - more than $10 \mathrm{MOhm}$.

These parameters meet the requirements for the thermal relays.

\section{POTENTIAL APPLICATIONS}

The thermorelays can be effectively used in a variety of thermosensitive devices:

- temperature indicators;

- the fire/heat detectors for fire alarm systems of installations, living accommodations, air-, railway- and motor-transport;

- thermal regulators in units for temperature control in greenhouses, grain elevators, vegetable stores and warehouses;

- sensors of liquids and pair overheating in cooling radiators, oil cooling jackets of industrial transformers, heat exchangers, steam boilers and cryogenic systems;

- temperature switches for car carburetors, radiators, ventilators and seats;

- thermo-drives in heat machines and refrigerators...

\section{References}

1. O.Mercier and K.N.Melton, Metall. Trans. A10, 387 (1979).

2. N.M.Matveeva, Yu.K.Kovneristy, Yu.A.Bykovsky, A.V.Shelyakov, and O.V.Kostyanaya, Izvestiya AN SSSR. Metally 4, 171 (1989).

3. T.H.Nam, T.Saburi, and K.Shimizu, Mater. Trans. JIM 31, 959 (1990).

4. A.V.Shelyakov, Yu.A.Bykovsky, N.M.Matveeva, and Yu.K.Kovneristy, J. de Phys.IV, C8(5), 713 (1995).

5. A.Shelyakov, A.Gulyaev, P.Potapov, E.Svistunova, D.Hodgson, N.Matveeva, and J.Cederstrom, in Proc. of Int. Conf. on Shape Memory and Superelastic Technologies (SMST-97), Pacific Grove, CA (USA), 2-6 March 1997, edited by A.R.Pelton, D.Hodgson, S.M.Russel and T.Duerig, (SMST, Santa Clara, CA, 1997), p.89.

6. A.V.Shelyakov, N.M.Matveeva, S.G.Larin, and V.V.Sokolovsky, New Technologies for 21 Century 1, 27 (1997).

7. P.Potapov, A.Shelyakov, A.Gulyaev, E.Svistunova, N.Matveeva, and D.Hodgson, Mater. Let. 32, 247 (1997).

8. H.Roesner, A.V.Shelyakov, A.M.Glezer, K.Feit, and P.Schlossmacher, Mater. Sci. Eng. A273-275, 733 (1999).

9. A.Shelyakov, N.Matveeva, and S.Larin, in Shape Memory Alloys: Fundamentals, Modeling and Industrial Applications, edited by F.Trochu and V. Brailovski, (Canadian Inst. of Mining, Metallurgy and Petrolium, 1999), p. 295.

10. Patent of Russian Federation, No. 2040819, Cl. H 01 H 37/46, 1993

11. Patent of Russian Federation, No. 2117354, Cl. H 01 H 37/46, 61/06, 1997 